\title{
1q21.1 Deletions and Duplications in 2 Siblings with Psychiatric Problems
}

\author{
Hande Kaymakçalan ${ }^{1}$ (D) Peining $\mathrm{Li}^{2}$ \\ Received: 26 January 2019 / Accepted: 11 June 2019 / Published online: 4 July 2019 \\ (C) Dr. K C Chaudhuri Foundation 2019
}

To the Editor: An 8-y-old girl was admitted for uncontrollable agressive behavior towards her family members. Two months later, her 6 y old brother was admitted with similar complaints.

The girl was diagnosed with attention deficit hyperactivity disorder (ADHD) and autism spectrum disorder (ASD). She had failure to thrive, mixed expressive and receptive language delay, mild mental retardation (IQ 60), encopresis and enuresis and poor sleep with only 3-4 h per day. She was microcephalic $(<3 \%)$, small for age (weight and height $<3 \%$ ) and had hyperextensible elbows. She had no other dysmorphic features. Fragile X testing, karyotype, biochemical and metabolic analysis were normal. We followed with a Chromosome Microarray Comparative Genomic Hybridization (CM-CGH) test with Agilent $144 \mathrm{~K}$. The analysis revealed an XX female sex chromosome and a copy number of two for chromosomes 1 to 22 , and according to GRCh38/hg38 breakpoints were $0.35 \mathrm{Mb}$ duplication (Chr 1: 145, 670, 852-146, 021, 841), $0.618 \mathrm{Mb}$ deletion (Chr 1: 147, 155, 106-147, 773, 362) at 1q21.1.

Her brother had bilateral sensorineural hearing loss. He was not dysmorphic, was normocephalic (50\%), weight and height were $25 \%$ and $50 \%$ for his age respectively. CM-CGH testing revealed XY male sex chromosome with 1q21.1 duplication and deletion which was similar to his sister.

Their parents were non-consanguineous; their 2 sisters and 2 brothers had hearing loss, one sister had bipolar disorder and one sister had ADHD. Father had depression, 2 maternal aunts and 1 paternal aunt had bipolar disorders.

Unfortunately, parents denied any testing on themselves and any other family member.

Hande Kaymakçalan

hande.kaymakcalancelebiler@demiroglu.bilim.edu.tr

1 Pediatric Genetics Unit, Department of Pediatrics, Demiroğlu Bilim Üniversitesi, İstanbul, Turkey

2 Department of Clinical Genetics, Yale University, New Haven, CT, USA
The association of recurrent rearrangements in 1q21.1 in variable pediatric phenotypes such as autism spectrum disorders (ASD), ADHD, congenital heart defects, cataracts, micro and macrocephaly, skeletal and genitourinary abnormalities and mild to moderate mental retardation has been shown by different authors [1-5].

Arrangements in this region show variable expressivity and incomplete penetrance. Inheritance is either autosomal dominant or de novo. Not testing the other family members is a limitation, but according to DECIPHER, the deleted and duplicated gene regions in our patients are pathogenic. In conclusion, children presenting with psychiatric problems and especially ASD and various physical problems, should be offered microarray testing.

\section{Compliance with Ethical Standards}

Conflict of Interest None.

\section{References}

1. Mefford HC, Sharp AJ, Baker C, et al. Recurrent rearrangements of chromosome 1q21.1 and variable pediatric phenotypes. N Engl J Med. 2008;359:1685-99.

2. Brunetti-Pierri N, Berg JS, Scaglia F, et al. Recurrent reciprocal 1q21.1 deletions and duplications associated with microcephaly or macrocephaly and developmental and behavioral abnormalities. Nat Genet. 2008;40:1466-71.

3. Bernier R, Steinman KJ, Reilly B, et al. Clinical phenotype of the recurrent 1q21.1 copy-number variant. Genet Med. 2016;18:341-9.

4. Busè M, Cuttaia HC, Palazzo D, et al. Expanding the phenotype of reciprocal 1q21.1 deletions and duplications: a case series. Ital J Pediatr. 2017;43:61.

5. Goodbourn PT, Bosten JM, Bargary G, Hogg RE, Lawrance-Owen AJ, Mollon JD. Variants in the 1q21.1 risk region are associated with a visual endophenotype of autism and schizophrenia. Genes Brain Behav. 2014;13:144-51.

Publisher's Note Springer Nature remains neutral with regard to jurisdictional claims in published maps and institutional affiliations. 